\title{
Soft Tissue Management on Pontic and Implant Sites Before Implants Insertion
}

\author{
Carlos Jurado ${ }^{1}$, Luis Guzman ${ }^{2}$, Chin-Chuan $\mathrm{Fu}^{2}$, Mohammed E. Sayed ${ }^{3}$, and Akimasa \\ Tsujimoto ${ }^{4}$
}

${ }^{1}$ Arizona School of Dentistry and Oral Health

${ }^{2}$ The University of Alabama at Birmingham School of Dentistry

${ }^{3}$ Jazan University

${ }^{4}$ Nihon University School of Dentistry Graduate School of Dentistry

February 27, 2021

\footnotetext{
Abstract

This report demonstrates a method for shaping the soft-tissue of pontic and future implant sites before implants placement. After non-restorable teeth were extracted, soft-tissue was contoured to achieve ovate-shape on pontic and implant areas. These initial contouring procedures allowed the shape of the soft-tissue to be evaluated before implant placement.

\section{Soft Tissue Management on Pontic and Implant Sites Before Implants Insertion}

Carlos Alberto Jurado, DDS, MS. ${ }^{1}$

Luis Guzman, DDS, MS, DMD. ${ }^{2}$

Chin-Chuan Fu, DDS, MS. ${ }^{3}$

Mohammed Sayed, BDS, MDS, PhD. ${ }^{4}$

Akimasa Tsujimoto, DDS, PhD. ${ }^{5}$

${ }^{1}$ Clinical Digital Dentistry. A.T. Still University Arizona School of Dentistry \& Oral Health, Mesa, Arizona, USA.

${ }^{2}$ Department of Periodontology, University of Alabama at Birmingham School of Dentistry, Birmingham, Alabama, USA.

${ }^{3}$ Department of Restorative Sciences, University of Alabama at Birmingham School of Dentistry, Birmingham, Alabama, USA.

${ }^{4}$ Department of Substitutive Dental Sciences, Jazan University College of Dentistry, Jazan, Saudi Arabia.

${ }^{5}$ Department of Operative Dentistry, Nihon University, Tokyo, Japan.

Acknowledgments

Authors would like to thank UAB Graduate Prosthodontics for their support and James Brandley for his laboratory support.

Correspondence

Carlos A. Jurado, DDS, MS.
} 
Prosthodontist \& Operative Dentist

Assistant Professor, Clinical Digital Dentistry

A.T. Still University Arizona School of Dentistry \& Oral Health

5855 East Still Circle, Mesa, AZ 85206

Phone: (480) 248 8152. Email: carlosjurado@atsu.edu

\section{Soft Tissue Management on Pontic and Implant Sites Before Implants Insertion}

\section{Key Clinical Message}

This report demonstrates a method for shaping the soft-tissue of pontic and future implant sites before implants placement. After non-restorable teeth were extracted, soft-tissue was contoured to achieve ovateshape on pontic and implant areas. These initial contouring procedures allowed the shape of the soft-tissue to be evaluated before implant placement.

Keywords: Implants, soft-tissue, contouring, esthetics, prosthesis, zirconia

\section{Introduction}

The esthetic management and preservation of tissue stability in the area surrounding implant abutments have been important topics for investigation and discussion. ${ }^{1,2}$ The esthetics of implants replacing the maxillary anterior teeth are particularly challenging as patients are very conscious of this area, and have high demands, especially for harmony between the implants and the soft tissue. ${ }^{3-5}$ Soft tissue management to achieve this has conventionally been performed after implant placement using implant-supported provisional restorations. ${ }^{6}$

However, when this is achieved through surgical shaping and pressure from the implant supported provisional restorations, the soft tissues surrounding implant and other pontic areas do conform the desired shape, but inflammation is a common complication especially in restoring spanning multiple teeth. ${ }^{7,8}$ This inflammation has several causes. The surgery and pressure themselves often lead to inflammation directly, and while this management is in progress the soft tissue and implants are not fully adapted to one another, leaving space where food particles can be retained and plaque develop, causing further inflammation. ${ }^{9}$ This inflammation could reduce the stability of osseointegration, and lead to periimplantitis. This case study demonstrates a technique for managing the soft tissue before implant placement, which should avoid these problems. The aim of this report is to evaluate the clinical outcome of soft tissue management before implant placement.

\section{Clinical Report}

A 45 years-old female patient presented to the clinic with the chief complaint "My front crowns are loose and they come off sometimes". The patient reported that she had had crowns made of porcelain fused to metal placed on teeth from the maxillary right lateral incisor to the left incisor, fifteen years ago. (Fig. 1) These crowns had become loose and come off sometimes; she used to cement them back with an over-the-counter remedy from the pharmacy. The papilla between the teeth was also decreased leading to black triangles between them.

After a detailed clinical evaluation, the maxillary right lateral incisor, both central incisors and left lateral incisor were diagnosed with mobility grade II, and incisal wear was found on the on maxillary right and left canines. Radiographic evaluation showed the old crowns and metal posts on the maxillary left latera incisor, both central incisors and right lateral incisor. The patient had high esthetic demands, and showed interest in having fixed all-ceramic restorations from maxillary right canine to left canine. The patient was informed of the need to remove the old crowns in order to re-asses the clinical situation of the teeth, and agreed to the procedure.

The existing restorations of the maxillary incisors were removed, and secondary caries was found in all teeth, with a fractured core on maxillary left central incisor, and mobility grade II on all teeth. Therefore, these teeth were deemed hopeless. (Fig. 2) The patient was informed of the option of having 2 implants in order 
to support a fixed prosthesis from maxillary left lateral to right lateral incisors, and single restorations on maxillary right and left canines. The patient approved the plan and the treatment was initiated.

A diagnostic wax-up was performed and a milled provisional restoration was fabricated for the span between maxillary canines. The maxillary canines were prepared, and the patient was sent for tooth extractions. The maxillary central and lateral incisors were extracted and particulate cortico-cancellous allograft bone (Cortical/Cancellous Chips, AlloSource Headquarters, Centennial, CO, USA) with collagen dressing (Puracol, Collagen Wound Dressing, Medline Industries Inc, Northfield, IL, USA) and resorbable sutures (Polysyn FA, Surgical Specialties Corporation, Wyomissing, PA, USA) was placed to achieve complete socket seal. (Fig. 3) The milled provisional restoration, made of polymethyl methacrylate, was cemented with an ovate pontic shape in the extraction sites, without interfering with the sutures. The initial provisional restorations applied a very light pressure, and included a space between the soft tissue and the provisional restoration to enable the patient to clean underneath the pontic and in the connector areas. (Fig. 4)

The patient returned two weeks later. The provisional was removed, and the pontic units were built-up using self-curing acrylic resin (Jet Tooth Shade, Lang Dental, Wheeling, IL, USA) in order to establish contact under slight pressure and maintain the developed ovate soft tissue contour, while the interproximal areas between the pontic units were opened with a disc (Acrylic Temporization System, Brasseler USA Dental, Savannah, GA. USA) in order to provide space for the papilla tissue. The patient returned again 2 weeks later and same procedure was performed.

Two months later, the patient was seen again for follow-up and the same procedure was performed. The thickness of the soft tissue was measured with a periodontal probe. (Williams Color-coded single end probe, Hu-Friedy Mfg. Co., LLC. Chicago, IL, USA) Carbide and diamond football burs (Medium Football bur, Brasseler USA Dental, Savannah, GA, USA) were used to improve the architecture of the pontic sites. (Fig. 5) The provisional restoration was built-up again using acrylic resin material (Acrylic Temporization System, Brasseler USA Dental, Savannah, GA, USA) in order to match the contour provided by the football burs. Two weeks later, the provisional restoration was removed to evaluate the final contour of the soft tissue. (Fig. 6)

The soft tissue achieved the desired shape and the implant therapy was planned using implant software (SimPlant, Dentsply Sirona Implants Inc, York, PA, USA). (Fig. 7) Two implants at the sites of maxillary right lateral incisor and maxillary left central incisor were planned to support a dental prosthesis from maxillary left lateral incisor to right lateral incisor. These sites were chosen based on the condition and thickness of the bone in the incisor region. Implant surgery was performed with palatally-oriented crestal incision and bilateral sulcular incisions on the canines to reflect a full muco-periosteal flap. The incision lines for the flap were planned to avoid damaging the soft tissue line created during the preparation. Two bone-level implants of size 4.1mm (BLT RC, Straumann Group, Basel, Switzerland) were inserted. (Fig. 8) A simple interrupted suture technique (Polysyn FA, Surgical Specialties Corporation, Wyomissing, PA, USA) was used for primary soft tissue closure. (Fig. 9) The implants were not loaded, and the existing fixed provisional restoration was cemented back on to the canines. During the two months of osseointegration, the provisional restoration maintained the soft tissue architecture that has been previously obtained.

After 4 months, the pontic sites of maxillary right lateral incisor and left central incisor were hollowed with acrylic carbide burs (Acrylic Temporization System, Brasseler, Savannah, GA, USA) in order to accept the temporary cylinders (Cylinder RC, Straumann Group, Basel Switzerland) engaged with the implants. The new screw-retained provisional restoration maintained the same tissue contour and three weeks later a final impression was made. (Fig. 10) The final restorations were screw-retained porcelain fused to zirconia to replace the incisors with zirconia abutments which were fixed to the titanium bases and single porcelain fused to zirconia crowns on the canines. Final restorations were tried-in for clinical and radiographic assessment, and patient satisfaction was achieved. Final implant restoration was placed and torqued according to the manufacturer instructions, while single crowns on maxillary right and left canines were cemented (RelyX Luting 2 Cement, 3M Espe, Saint Paul, MN, USA).Occlusion was checked and adjusted as necessary. Patient was satisfied with the final outcome. (Fig. 11) A night guard was provided in order to protect the dentition 
and final restorations.

\section{Discussion}

This technical report introduced a different approach for soft tissue contouring for implants in the esthetic zone. Traditionally, peri-implant tissue is contoured after the insertion of the implant placement. However, soft-tissue contouring prior to implant placement may provide a more predictable outcome in the final tissue architecture for pontic and implant areas before the endosteal implants are inserted. Patient and clinician can evaluate success and limitations prior to implant placement. It may also shorten the time required for tissue contouring with implant provisional restorations.

Optimal esthetics for implant therapy could be achieved by proper 3-dimensional planning, ideal implant depth in relation to adjacent teeth and peri-implant soft tissue molded by the provisional prosthesis. ${ }^{10,11}$ Immediate implant placement with provisional restoration is a common procedure in which the goal is to stablish an ideal emergence profile with maximum tissue volume, preserving mid-facial gingiva and enhancing patient comfort and acceptability. ${ }^{12,13}$ This then serves as a guide for designing and fabricating the final restoration. ${ }^{14}$ However, the present report has shown that all these goals could be achieved on pontic and implant sites before the implants are inserted.

After soft tissue is ideally as described in this report, it would be possible to perform flapless implant placement. This is suitable for patients with sufficient keratinized gingival tissue and bone volume in the implant recipient site. It has been reported that flapless implant placement approach minimizes postoperative peri-implant tissue loss, and therefore reduces the difficulties of the soft tissue management after the surgical intervention. ${ }^{15}$ In addition, flapless implant approach may cause less traumatic surgery, decreases operative time, provides faster postsurgical healing and fewer complications after surgery, and provides more comfort to the patient. ${ }^{16,17}$ However, implanting through the prepared soft tissue risks damaging the prepared areas, rendering the prior treatment meaningless. If a flap is used, a very simple secondary operation to create a hole for the implant is sufficient, reducing the potential damage to the shaped soft tissue. This has further advantages in allowing a clear view of the surgical site ${ }^{18}$ and the full penetration of irrigation water to the osteotomy, preventing thermal damage. Thus, we chose to use open flap surgery in this case, and the results were satisfactory. Nevertheless, it would be useful to investigate the combination of this contouring procedure with flapless implant placement to determine the best overall technique.

The design of the flap used in this case was based on two main considerations. Conventional open-flap dental implant therapy cuts the soft tissue on a line passing through the center of the implant location. However, in this case the incision was made around the edge of the gingival tissue, creating a single flap that lifted off the area. First, this avoided any damage to the shaped soft tissue that might result from an incision passing through that area. Second, by moving the sutured area away from the implant, it reduced the risk of infection in the newly-placed implant while the incisions were healing. This may have contributed to the successful outcome. However, the choice of incision location is influenced by many factors, and this approach may not be suitable in some cases.

Following this protocol, the clinician and patient can see the future final tissue contour in the pontic sites before implant placement. This will enable both sided to agree on an appropriate strategy to achieve the desired esthetics if there are shortcomings in the remaining soft tissue.

\section{Conclusions}

Soft tissue contouring for implant restorations may be challenging, however contouring the tissue prior implant placement may provide a more predictable outcome in the final tissue architecture. This sequence allows patient and clinician can evaluate success and limitations prior to implant placement.

\section{References}

1. Wallner G, Rieder D, Wichmann MG, Heckmann SM. Peri-implant bone loss of tissue-level and bone-level implants in the esthetic zone with gingival biotype analysis. Int. J. Oral Maxillofac. Implant. 2018;33:1119- 
1125. doi:10.11607/jomi.6641.

2. Bosshardt DD, Chappuis V, Buser D. Osseointegration of titanium, titanium alloy and zirconia dental implants: Current knowledge and open questions. Periodontol. 2000. 2017;73:22-40. doi:10.1111/prd.12179

3. Becker CM, Wilson TG Jr, Jensen OT. Minimum criteria for immediate provisionalization of single-tooth dental implants in extraction sites: a 1-year retrospective study of 100 consecutive cases. J Oral Maxillofac Surg. 2011;69:491-497. doi:10.1016/j.joms.2010.10.024.

4. Priest G. Esthetic potential of single-implant provisional restorations: selection criteria of available alternatives. J Esthet Restor Dent. 2006;18:326-338. doi:10.1111/j.1708-8240.2006.00044.x .

5. Becker W, Goldstein M. Immediate implant placement: treatment planning and surgical steps for successful outcome. Periodontol. 2000. 2008;47:79-89. doi:10.1111/j.1600-0757.2007.00242.x .

6. Testori T, Weinstein T, Scutellà F, Wang HL, Zucchelli G. Implant placement in the esthetic area: criteria for positioning single and multiple implants. Periodontol 2000. 2018;77:176-196. doi:10.1111/prd.12211 .

7. Ramanauskaite A, Roccuzzo A, Schwarz F. A systematic review on the influence of the horizontal distance between two adjacent implants inserted in the anterior maxilla on the inter-implant mucosa fill. Clin Oral Implants Res. 2018;29:62-70. doi:10.1111/clr.13103.

8. Edelhoff D, Spiekermann H, Yildirim M. A review of esthetic pontic design options. Quintessence Int. 2002;33:736-746.

9. Krennmair G, Seemann R, Weinländer M, Wegscheider W, Piehslinger E. Implant-prosthodontic rehabilitation of anterior partial edentulism: a clinical review. Int J Oral Maxillofac Implants. 2011;26:1043-1050.

10. Grunder U, Gracis S, Capelli M. Influence of the 3-D bone-to-implant relationship on esthetics. Int J Periodontics Restorative Dent. 2005;25:113-119.

11. Jurado CA, Tsujimoto A, Guzman LG, Fischer NG, Markham MD, Barkmeier WW, et al. Implant therapy with ultratranslucent monolithic zirconia restorations in the esthetic zone: a case report. Gen Dent. 2020;68(1):46-49.

12. Esposito M, Grusovin MG, Polyzos IP, Felice P, Worthington HV. Interventions for replacing missing teeth: dental implants in fresh extraction sockets (immediate, immediate-delayed and delayed implants). Cochrane Database Syst Rev. 2010;CD005968. doi:10.1002/14651858.CD005968.pub3 .

13. De Rouck T, Collys K, Cosyn J. Single-tooth replacement in the anterior maxilla by means of immediate implantation and provisionalization: a review. Int J Oral Maxillofac Implants. 2008;23:897-904.

14. Salama H, Rose LF, Salama M, Betts NJ. Immediate loading of bilaterally splinted titanium root-form implants in fixed prosthodontics-a technique reexamined: two case reports. Int J Periodontics Restorative Dent. 1995;15:344-361.

15. Rocci A, Martignoni M, Gottlow J. Immediate loading in the maxilla using flapless surgery, implants placed in predetermined positions, and prefabricated provisional restorations: a retrospective 3-year clinical study. Clin Implant Dent Relat Res. 2003;5:29-36.

16. Sunitha RV, Sapthagiri E. Flapless implant surgery: a 2-year follow-up study of 40 implants. Oral Surg Oral Med Oral Pathol Oral Radiol. 2013;116:e237-e243. doi:10.1111/j.1708-8208.2003.tb00013.x.

17. Arisan V, Karabuda CZ, Ozdemir T. Implant surgery using bone- and mucosa-supported stereolithographic guides in totally edentulous jaws: surgical and post-operative outcomes of computer-aided vs. standard techniques. Clin Oral Implants Res. 2010;21:980-988. doi:10.1111/j.1600-0501.2010.01957.x . 
18. De Bruyn H, Atashkadeh M, Cosyn J, van de Velde T. Clinical outcome and bone preservation of single TiUnit implants installed with flapless or flap surgery. Clin Implant Dent Relat Res. 2011;13:175-183. doi:10.1111/j.1708-8208.2009.00200.x .

\section{Figure Legends}

Figure 1. Initial clinical situation

Figure 2. Radiographic evaluation and crowns removal.

Figure 3. Teeth extraction.

Figure 4. Initial provisional restoration contouring the tissue.

Figure 5. Soft tissue contouring with diamond and carbide burs.

Figure 6. Soft tissue contoured.

Figure 7. Implant planning.

Figure 8. Implant placement.

Figure 9. Suturing and provisional placement.

Figure 10. Final provisional restoration and contour.

Figure 11. Final ceramic restorations.
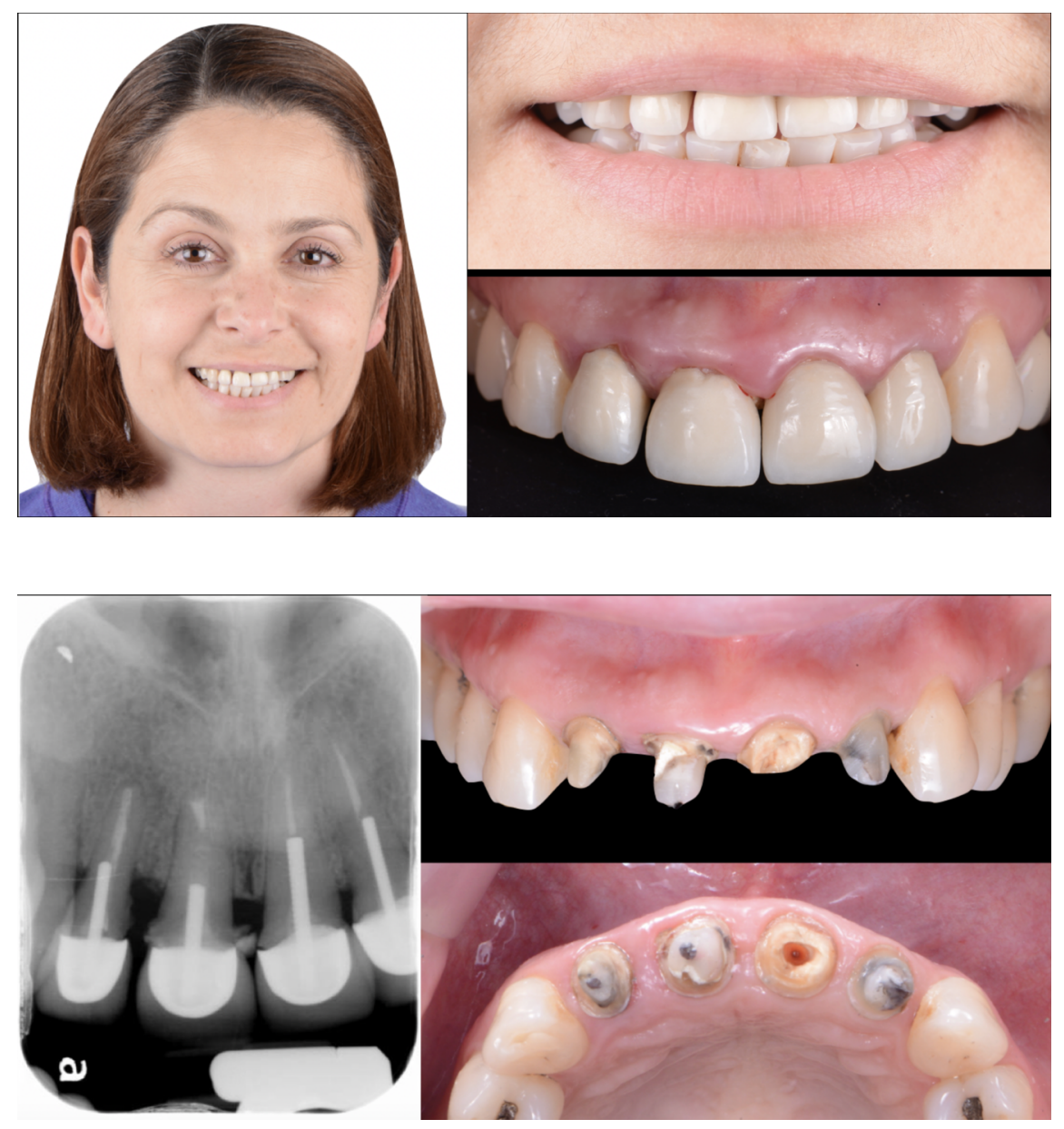


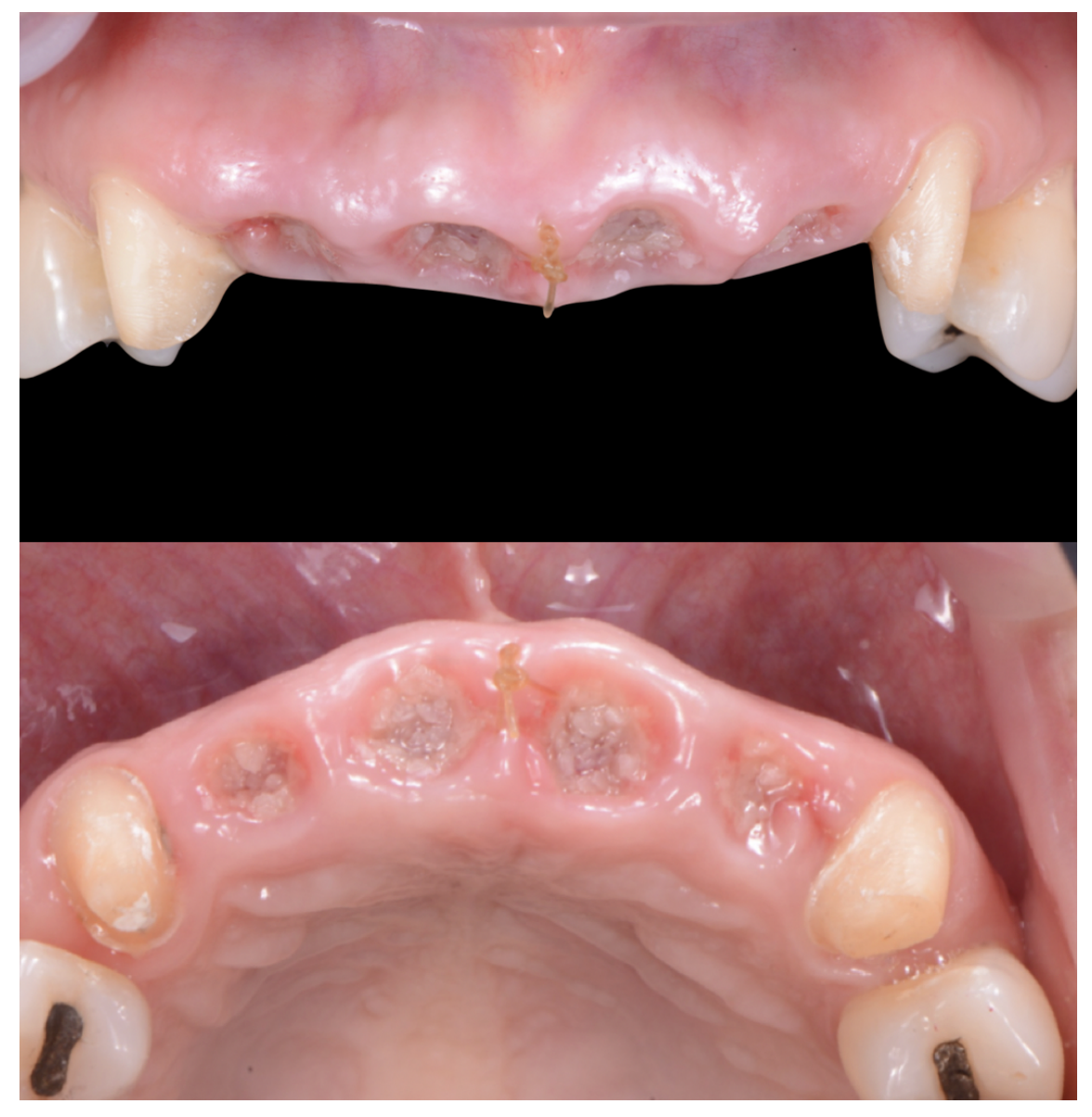




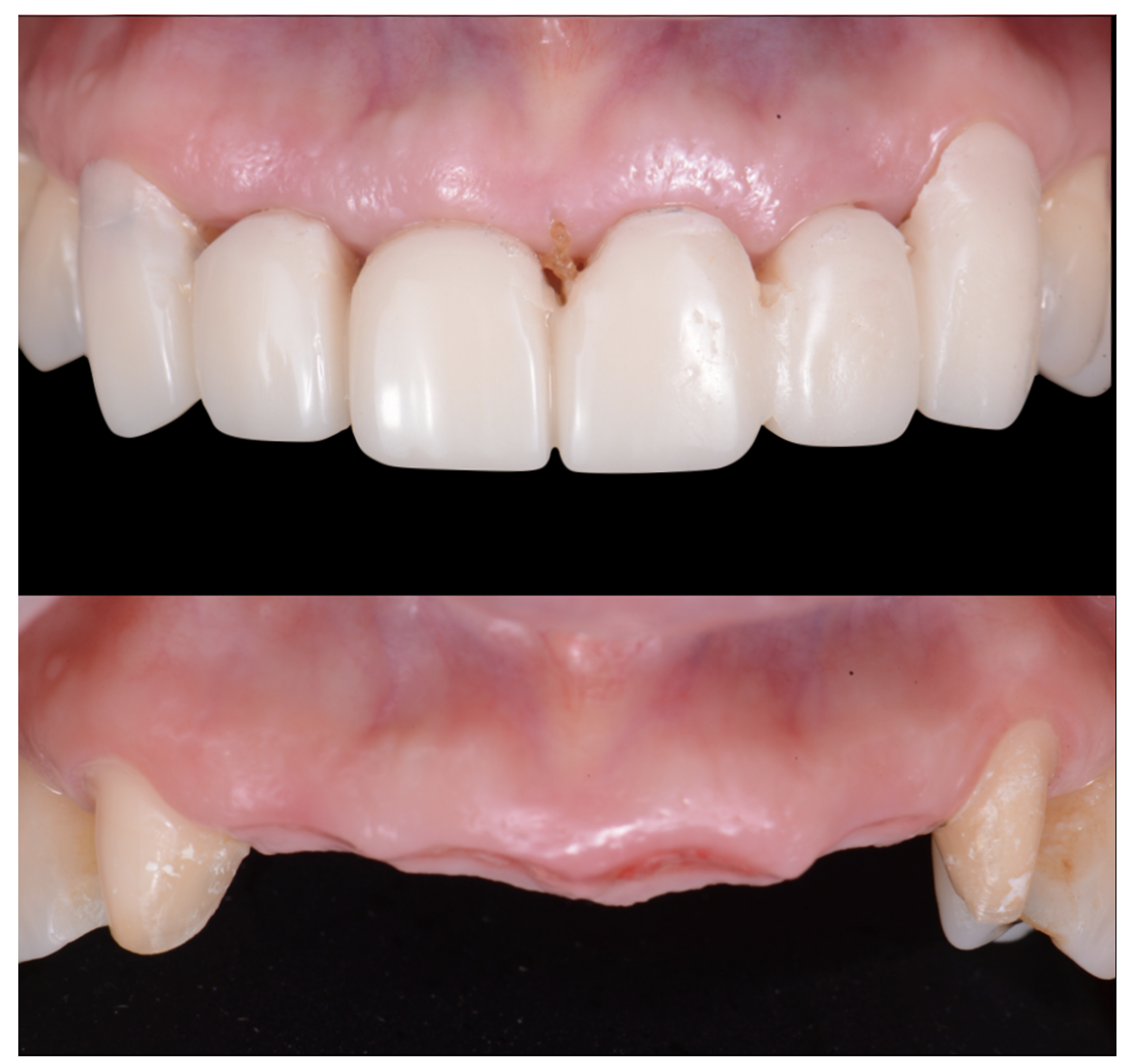



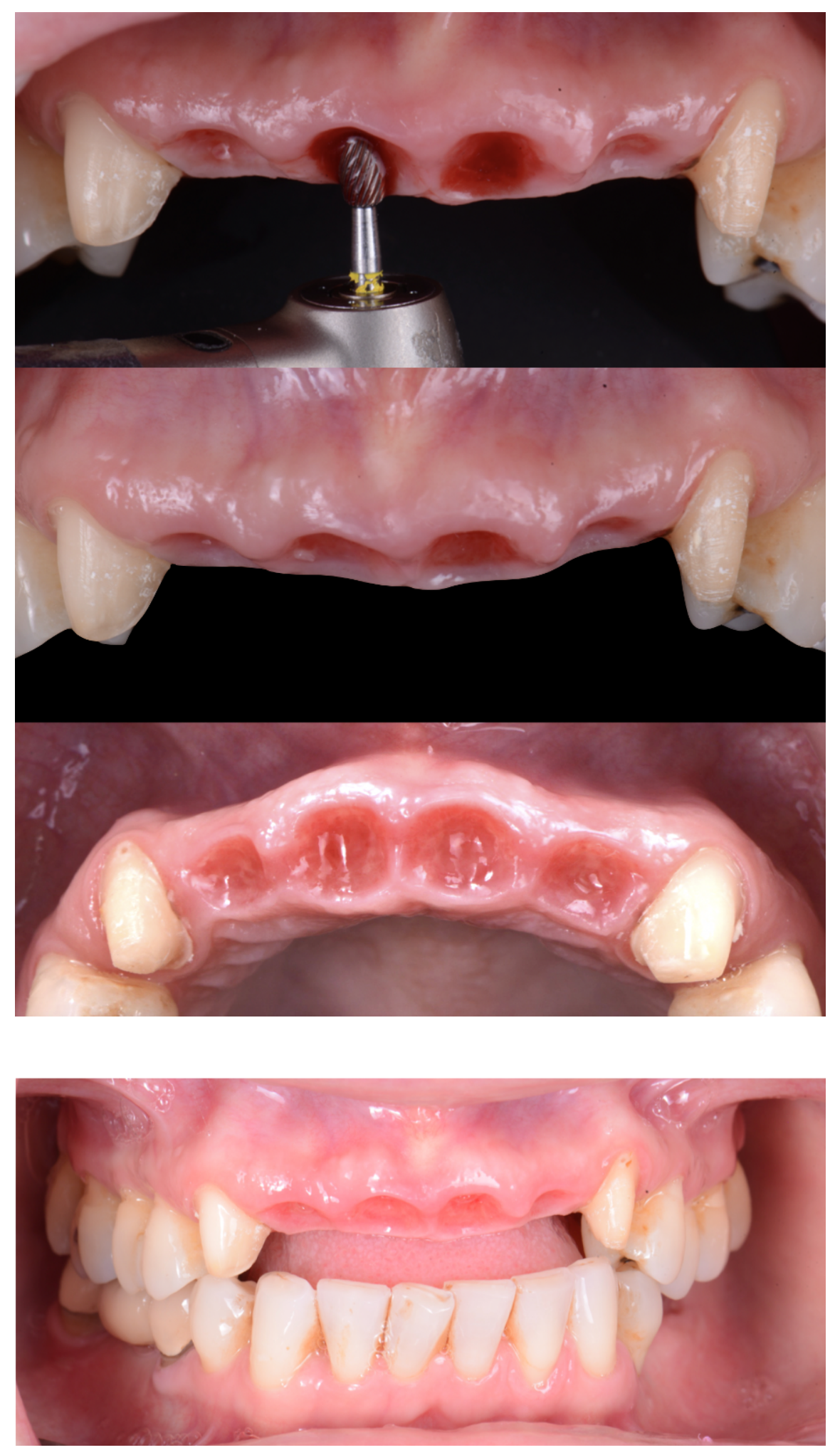


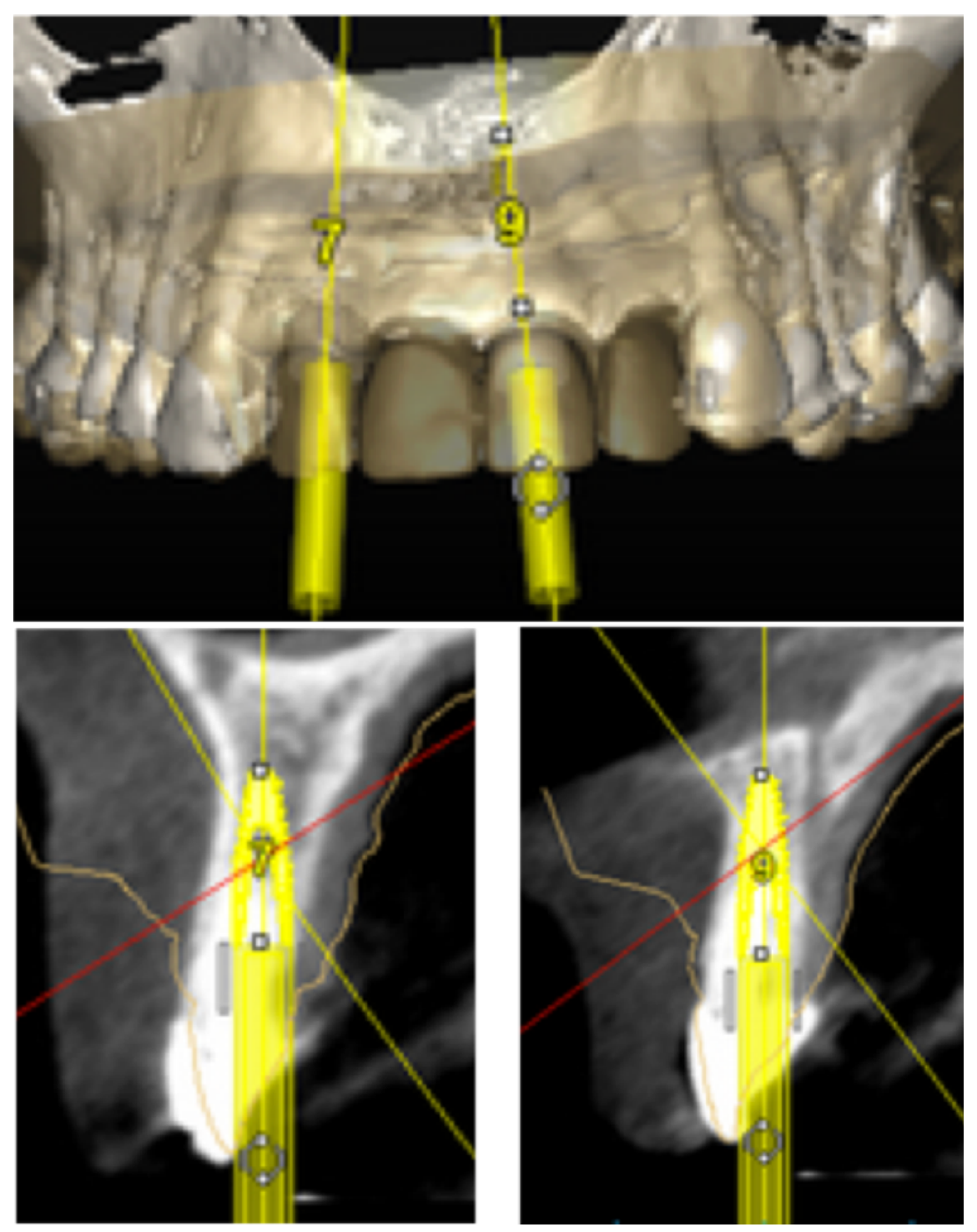




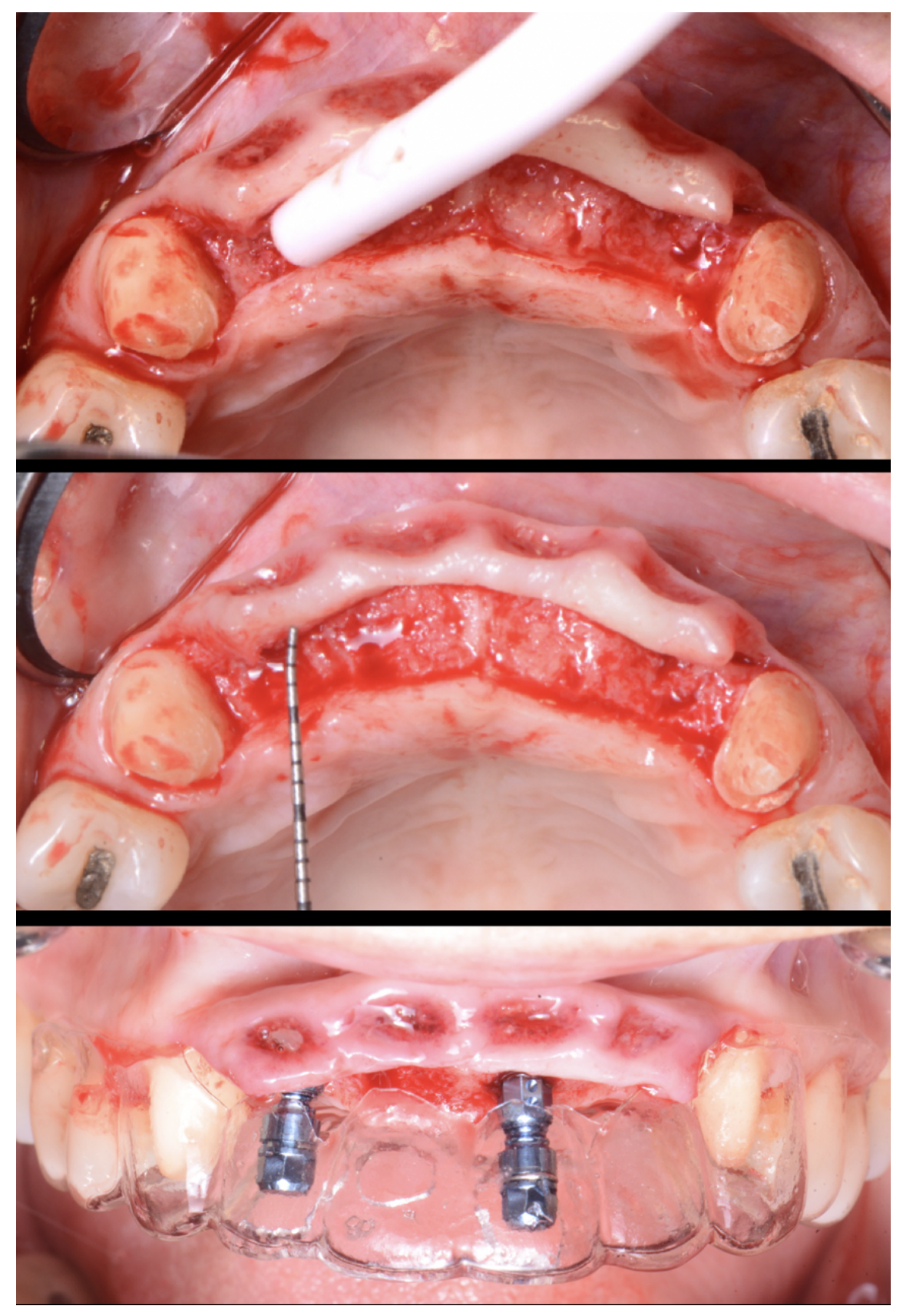




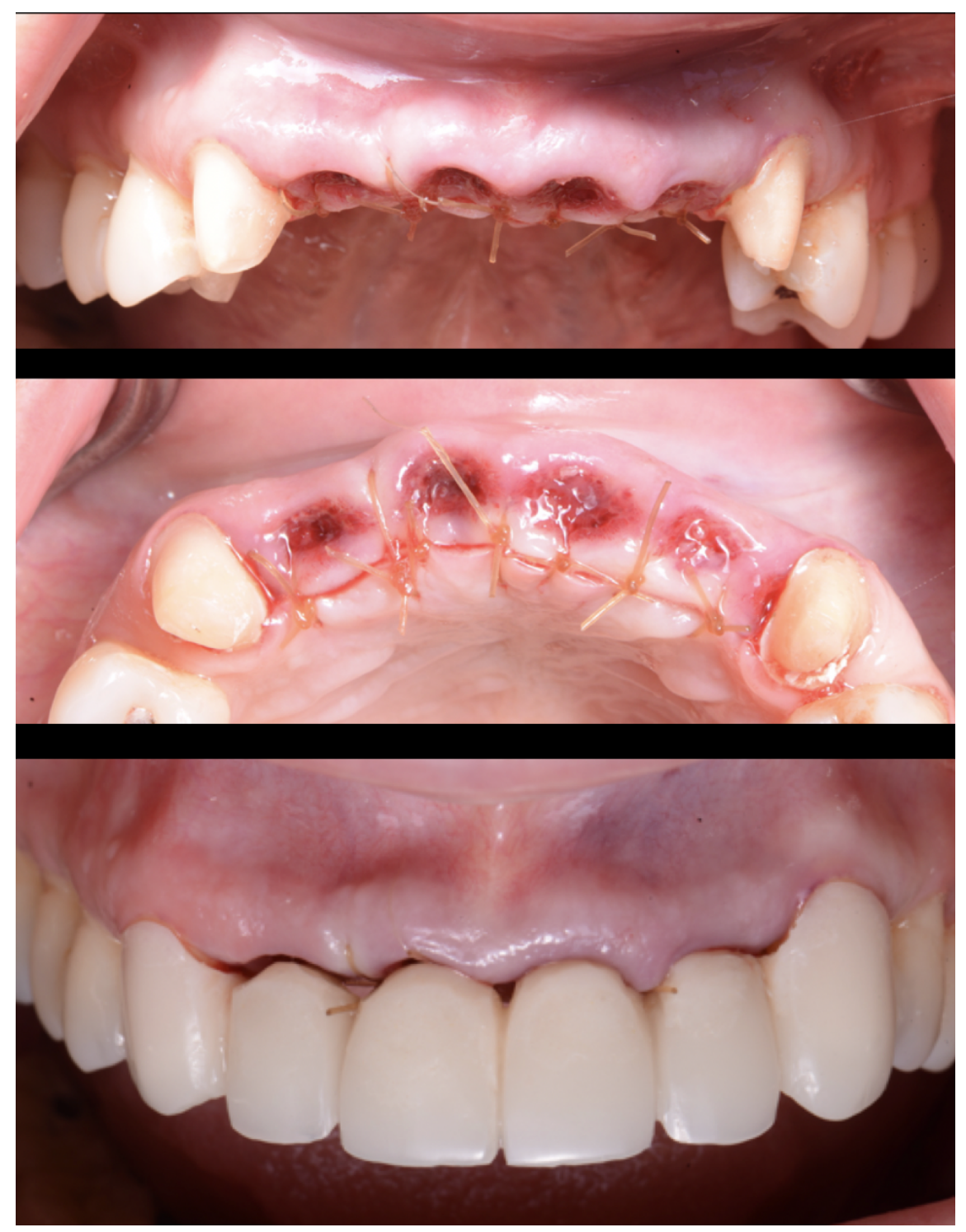



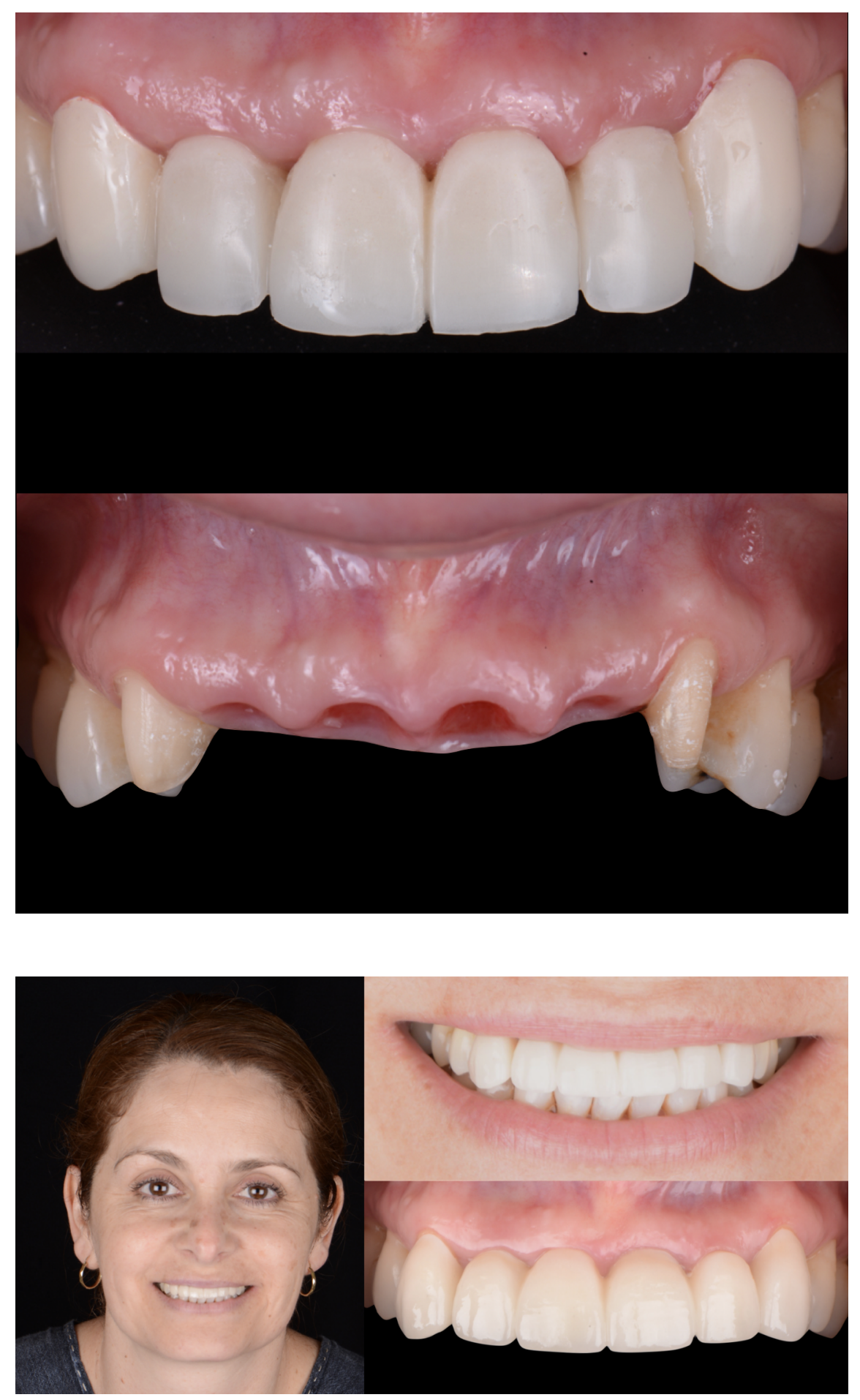